\title{
STEM Faculty Experiences with Students with Disabilities at a Land Grant Institution
}

\author{
Tyler S. Love, Nicole Kreiser, Elsa Camargo, Michael E. Grubbs, Eujin Julia Kim, Penny L. Burge, Steven M. Culver
}

\author{
Received: October 31, 2014 Accepted: November 17, 2014 Online Published: December 8, 2014 \\ doi:10.11114/jets.v3i1.573 \\ URL:http://dx.doi.org/10.11114/jets.v3i1.573
}

\begin{abstract}
Preparing faculty to meet the needs of the increasing number of students with disabilities is a critical need in higher education, particularly in the STEM (science, technology, engineering, and mathematics) fields. Quality preparation is an emerging problem as the number of higher education students with disabilities is on the rise. In this study, researchers used a qualitative methodology to examine STEM faculty members' experiences with students with disabilities at a land grant institution in the southeastern United States. The study was conducted to answer the following questions: (a) What experiences, positive and negative, have STEM faculty members had working with students with disabilities?(b) How do STEM faculty members describe students with disabilities?, and (c) What resources do faculty members need to adequately serve students with disabilities? Five researchers conducted individual interviews with STEM faculty members. Interviews were transcribed and analyzed, with the following themes emerging from the data: Challenges, Support, Knowledge, Awareness/Visibility, and Formal versus Informal Accommodations. Implications from this study relate to the improvement of services for students with disabilities at higher education institutions and to the preparation of STEM faculty to accommodate their students.
\end{abstract}

Keywords: students with disabilities, STEM, higher education, accommodations

\section{Introduction}

\subsection{Introduction to the Problem}

Science, technology, engineering, and mathematics (STEM) fields are areas that seen as making substantial contributions to an array of issues from health care to the environment. Recently, President Obama emphasized the importance of a STEM-trained workforce calling it, "essential to every goal we have as a nation" (Larson, 2012, para. 2). Further, STEM education is grounded in problem-solving skills that correlate to real life experiences that students will encounter in their future careers. Despite this national emphasis and the increasing demand for STEM majors, fewer American college students are pursuing these fields. In 1980, 30\% of U.S. bachelor degrees awarded were in STEM fields, but in 2007 that number dropped to 23\%. Furthermore, for those in STEM fields, attrition rates are high: nearly half $(48 \%)$ of bachelor's level students who initially majored in STEM areas between 2003 and 2009 switched to other non-STEM majors before graduation (Chen, 2013).

Students with disabilities are one of the subpopulations that face the typical issues of pursuit of STEM degrees but in addition they face additional systematic barriers. For example, students with disabilities struggle with the development of these skills generally (Street et al., 2012), which is why it is essential that they receive the proper accommodations and assistance from faculty. When higher education professionals re-examine how faculty members are prepared they can more likely assure equal educational opportunities for all students, and focus on graduating more STEM majors, essential for success in international STEM careers (Arscott, 2013; Lombardi \& Murray, 2011; Thomas, 2000). Research examining higher education STEM faculty members' experience with students with disabilities is needed due to the lack of prior research in this area.

\subsection{Relevant Literature}

The transition from high school to college is a difficult one for all students, especially those with disabilities because of challenges such as academic and social adjustment (Alcorn MacKay, 2010). Six years after high school, only 55\% of students with disabilities had attended some type of college as opposed to $62 \%$ of students without disabilities (Shah, 2011). Access to higher education for students with disabilities is also a concern in the U.S. because of the increasing number of students diagnosed with a disability (U.S. Government Accountability Office, 2009). In 2011, 6.53 million U.S. students between 3-21 years old were served under the Individuals with Disabilities Education Improvement Act 
(IDEIA) (2004), with approximately 370,000 of those students served being between 18-21 years old (U.S. Department of Education, 2011). The number of students diagnosed has increased 30\% from ten years earlier (Arscott, 2013), and 11\% of undergraduate college students reported having a disabling condition (Street et al., 2012). Among U.S. college students with disabilities, $31 \%$ were learning disabilities, $18 \%$ were ADD/ADHD, $15 \%$ were mental illness/psychological or psychiatric conditions, and 11\% were health impairments (U.S. Department of Education, 2012). Arscott (2013) found that learning disabilities were the fastest growing and most reported group at the university level, and the largest disability group seeking access to higher education. These statistics show the vast array of disabilities that students are diagnosed with and that higher education faculty members must be knowledgeable about in order to work with all students. This presents a challenge for faculty preparation programs and higher education institutional leaders to ensure faculty and staff are prepared to assist students with all types of disabilities.

Accommodating students with disabilities in higher education has been a focus that policy makers have struggled to address for years. Current U.S. law has not been fully successful in helping higher education students with disabilities. Students with disabilities experience great difficulty transitioning from high school to higher education due to differences in laws implemented at each level (Ochoa, 2007). Students in P-12 are minors with parents advocating and supporting them. When they enter higher education they become legal adults expected to advocate for themselves. Also, P-12 education is considered a right in the U.S. Higher education on the other hand is viewed as a privilege, as is reflected in current law. For example, the IDEIA (2004) mandated Individualized Education Plans (IEPs) including transition activities to promote effective movement from school to post-school activities, including higher education and the work force. However, Section 504of the Rehabilitation Act (1973) and the Americans with Disabilities Act (ADA) (1990) require higher education institutions to provide equal access to education (U.S. Government Accountability Office, 2009). They do not require individual accommodations and IEPs. Students in higher education must self-disclose their disability, provide documentation, and request accommodations and services; in P-12 the school is responsible for identifying, locating, and evaluating students who may have a disability (U.S. Government Accountability Office, 2009).

Among higher education institutions the steps to obtain accommodations vary. Institutions are required to provide "reasonable accommodations tailored to an individual student's needs to allow equal access to higher education" (Government Accountability Office, 2009, p. 13). While institutions are required to provide reasonable accommodations and bear the cost, they "are not required to provide accommodations that would fundamentally alter the nature of a program, lower or waive essential academic requirements, or result in undue financial or administrative burdens" (U.S. Government Accountability Office, 2009, p. 4). They are required to have an individual or office that coordinates the institution's compliance with the Rehabilitation Act (1973) and ADA (1990). Institutions must also have a grievance procedure to assure students can fully and fairly raise concerns to be remedied with prompt and equitable resolutions (Government Accountability Office, 2009).

Higher education institutions comply with these requirements in various ways. Most institutions have a disabilities office to provide and facilitate services for students with disabilities and communicate with faculty and other campus offices. School officials believe that collaboration among the disabilities office, other school offices, and groups in the community is the greatest advantage of having a disabilities office on campus (Government Accountability Office, 2009). Some institutions offer additional services, such as counseling and tutoring, disability screening and assessment, workshops on essential learning skills, and mentoring. Specialized programs (e.g., Learning Services Program) to supplement academic instruction are additional services some institutions provide. Outside private organizations offer personalized fee-based services such as mentoring and personal advocacy for students with disabilities. Lastly, advancements in technologies to assist students with disabilities has caused some institutions to provide assistive technology departments that provide training sessions to educate faculty on using these technologies to accommodate students (Government Accountability Office, 2009).

Unlike P-12 teachers, higher education faculty are less involved in the accommodation process. A faculty member only has to provide reasonable accommodations if a student self discloses their disability with documentation or if the disabilities office on campus contacts the faculty member. The disabilities office often works closely with the faculty to make them aware of students in their courses who have disabilities, the nature of their disability, and required accommodations. The disabilities office also works with the student and the faculty to obtain required resources. Once a faculty member is notified by the student or by the disabilities office of the student's disability, they are required to provide the accommodations specified by the disabilities office. Faculty members' lack of experience working with students with disabilities, and lack of awareness and understanding of legal requirements has caused faculty members to be resistant toward providing legally mandated accommodations. The disabilities office serves as the liaison between the student and faculty to assure the student is receiving the proper accommodations. Despite differences in P-12 and higher education, there are valuable lessons to be learned from examining the laws at both levels. Eventually, the laws and court rulings regarding students with disabilities at the P-12 level can emerge to influence higher education laws and policies 
(Janosik, 2005; Love, 2014; Love, 2013) and help accommodate the increasing number of students with disabilities entering higher education.

Despite the inability of U.S. lawmakers to mandate a procedure assuring each student entering higher education with a disability is identified and receives an individualized education plan like in P-12, more students with disabilities continue to enter higher education and the workforce (Arscott, 2013; Thomas, 2000). When higher education leaders help to accommodate these students, more students will be college and career ready for critical shortage areas such as STEM. Most higher education faculty members are not required to complete special education courses or a teaching internship prior to teaching in higher education. In fact, they often have little or no experience working with students with disabilities prior to working in higher education (Norman, Caseau, \& Stefanich, 1998; Government Accountability Office, 2009). Finding out what experiences faculty members had and how they can be better supported to work with these students is critical to higher education, STEM majors, and the workforce.

Limited research has been conducted regarding STEM students with disabilities in higher education and this research has focused on the roadblocks that students face - lack of role models, limited exposure to appropriate prerequisite courses, and lack of access to individualized supports (Dunn, Rabren, Taylor, \& Dotson, 2012). Some research has been conducted on different types of instructional models, such as online accommodations for students (Phillips, Terras, Swinney, \& Schneweis, 2012) and a peer-learning model to accommodate STEM students with disabilities (Street et al., 2012). However, little research has focused on faculty members' attitudes, knowledge and skills related to students with disabilities. Further research is needed examining faculty members' challenges to assist students with disabilities (Baker, Boland, \&Nowik, 2012) as well as working with students with disabilities within STEM majors (Street et al., 2012). Specifically examining STEM faculty at a land grant institution has not been done, so a qualitative approach was used to provide an initial look at faculty perceptions and to lay the foundation for future studies (Rossman \& Rallis, 2012). As recommended by Seidman (2012), interviewing provides an in-depth understanding of the lived experiences of interviewees (faculty) that cannot be teased out through a quantitative study.

\section{Methods}

The purpose of this study was to investigate STEM faculty members' experiences with students with disabilities at a land grant institution in the U.S. As suggested by Rossman and Rallis (2012), to elicit thick, rich, and detailed data the researchers used a qualitative approach. Results are presented as narratives about the interviewed faculty and as a discussion of themes that emerged from the interview data. To assist in addressing the purpose of this research interview questions and data analysis were designed around the following research questions:

1. What experiences, positive and negative, have STEM faculty members had working with students with disabilities?

2. How do STEM faculty members describe students with disabilities?

3. What resources do STEM faculty members need to adequately serve students with disabilities?

The research team included five graduate students pursuing doctoral degrees in different concentrations (i.e., Psychology, Environmental Design and Planning, Curriculum and Instruction, and Higher Education Administration). No interviewer had previously met their interviewee. The team was comprised of two males and three females. Given the nature of the disciplines represented by the researchers and researchers' experience with students with disabilities (i.e., three of the researchers had prior experiences working with students with disabilities and all researchers plan to have future experiences interacting with students with disabilities in a helping profession), the researchers believed in the importance of inclusion and accommodation of students with disabilities in higher education. The research team collected, analyzed, and reflected upon the data in relation to the literature and themes that emerged from the interviews.

\subsection{Participants}

Faculty members representing the STEM disciplines were recruited from a U.S. land grant institution using a purposeful sampling method. The researchers selected five individuals who volunteered for the study and who have taught students with disabilities at that institution. Two participants were from science fields, two from engineering fields, and one from technology education. There were four females and one male, with experience in higher education ranging from seven to seventeen years. Two faculty members identified as Caucasian, one as Hispanic, one as Middle Eastern, and one did not disclose their ethnicity. They were asked to participate in an interview related to their experiences with students with disabilities. Demographic information about each person was collected immediately before the interview using a hard-copy demographic questionnaire.

\subsection{Data Collection}

In addition to demographic questionnaires, the primary data were also collected from the interviews. The interviews focused on STEM instructors' and professors' experiences with students with disabilities. Using a qualitative interview 
approach helped the researchers better understand the faculty's experiences with students with disabilities. Purposeful sampling was used to recruit participants and criteria were chosen ahead of time to ensure participants would share appropriate experiences. Recruitment criteria included faculty who currently teach at a land grant institution, had experiences teaching students with disabilities, and were willing to respond to the researchers' questions.

The researchers used a face-to-face semi-structured interview format when collecting data and created questions to guide the interview with appropriate prompts thereafter. Once participants were recruited, the researchers arranged the interviews and allowed the participants to choose the location, which in all cases were their offices. Prior to beginning the interview, participants were given a copy of a consent form and demographic questionnaire. All interviews were audio recorded and later transcribed by the researchers. In order to maintain confidentiality, each participant was assigned a pseudonym. All researchers used the same interview protocol.

\subsection{Data Analysis}

Data were analyzed by all of the researchers in a systematic process to ensure immersion and triangulation. The initial stage of data analysis began with each researcher reading and re-reading their interview transcript. All researchers used open coding to create initial codes from utterances in the interviews to help capture patterns or similar experiences within the interviews. These codes were analyzed to form categories, which were then arranged into initial themes emerging from the interview.

After coding their own transcripts, researchers then coded the transcripts from the other team members. Once this step was completed, all researchers met to further analyze the data and identify common themes that emerged across the transcripts. During this process, some initial themes became sub-themes as they were condensed with similar concepts and codes, allowing for similar utterances within the transcripts to be categorized. As suggested by Kvale and Brinkmann (2015), using this community of practice approach allowed the researchers to learn from each others' feedback and improved judgment and reasoning.

\section{Findings}

In order to describe the unique background and experience each participant had working with students with disabilities, each researcher provided a narrative about the person they interviewed. These narratives included information from the demographic questionnaire and significant information shared during the interview. After the interviews were analyzed, findings were organized into themes. The researchers identified five themes from related sub-themes that emerged across the interviews, and provided narratives with background information about each participant.

\subsection{Participant Narratives}

Helen was a professor in one of the STEM colleges. Prior to entering higher education, she began her career as a scientist and researcher at various institutions. Helen has been at this institution for 15 years and has held various roles including Assistant Professor, Associate Dean, and Vice President for a department within the College of Science. She stated that her most recent focus had shifted from research towards teaching STEM education. Although a member of her family has an intellectual disability, Helen herself has not been diagnosed with a disability. Helen had no formal training or educational courses related to students with disabilities; however, she had searched alternative strategies on her own and contacted the institution's disability office. Helen described changing her pedagogical strategies and had gone from large direct instruction classes to more student centered learning environments to better accommodate all students' learning styles. She expressed interest in working with students with disabilities because of the changes she had seen in her various positions during her career.

Karen had been a professor in a STEM field at this institution for close to 20 years. This topic intrigued her because she wanted to know more about working with students with disabilities and how to obtain additional resources. Karen was eager to share her experiences to inform higher education institutions about her struggles and help improve accommodating students with disabilities. Karen did not disclose whether or not she had a disability. However, she reported that no one in her family had a disability. She had a bachelor's degree in education, but had not received previous training for working with students with disabilities. Throughout her career she had taught a variety of science courses. At the time she taught introductory courses. Karen had learned about disabilities on the job. During her years at this land grant institution, she had seen how technical support for working with students with disabilities had become more formal. Karen was interested in the institution continuing to increase the amount of professional development offered to further educate faculty about students with disabilities.

Mary was an academic and career advisor in one of the STEM colleges. She previously worked in a college outside of STEM. Mary possessed a bachelor's degree in social work, and a master's degree in higher education administration from this land grant institution. Although Mary chose not to disclose whether or not she had a disability on the demographic questionnaire, she did report that no one in her family had a disability. Mary had taken courses about students with 
disabilities during her coursework for her administration degree, through the National Academic Advising Association (NACADA), diversity workshops offered by the institution, and from the international resource center at the institution. Besides serving as an academic and career advisor for students, she taught an introductory level class in her college with approximately 250 students a semester. She stated that she had the opportunity to work with students with disabilities in her advising role, and also in her teaching role. She believed both were distinct experiences and they provided a unique background for working with these students. This topic was appealing to her because she believed that all students deserve an equal opportunity to an education. She hoped that her participation in this study would help elicit changes to make higher education more accessible to students with disabilities.

Patricia was an associate professor in one of the STEM colleges, and had received both her undergraduate and graduate degrees in engineering. She has been a professor at this institution for approximately seven years. Patricia taught both large undergraduate introductory level STEM courses and small graduate level seminar courses. Neither Patricia nor any of her family members had a disability, and she reported that prior to teaching at this land grant institution she had no previous personal experience with students with disabilities. Patricia had no formal training or educational courses related to students with disabilities, and had minimal interaction with the institution's disability office. She spoke quite openly about her lack of knowledge related to students with disabilities and minimal knowledge of pedagogical strategies to accommodate students with a range of learning styles. Patricia's interest in participating in this study was to learn more about how to accommodate students with disabilities and adjust her practices.

Peter was an assistant professor in a STEM education department. He graduated with an undergraduate degree in technology and human resource development with a minor in special education. He received his master's and doctoral degrees in technology education. He had a personal connection with this topic through his wife, who was a special education professional, as well as his own background and professional preparation. His preparation included a traditional licensure program and classroom experience teaching at the middle school and high school levels. He taught graduate level courses at this land grant institution. Neither he nor anyone in his family had a disability. He showed interest through his explanation of the overlap between this research topic and his personal research interests. Peter expressed that working with students with disabilities was a research area that he tries to tie into every study he conducts. He was a member of numerous national and international organizations, served on many editorial review boards, and served on various professional organization executive boards. Due to his background and experience, Peter believed that more higher education faculty members need to advocate for the rights of students with disabilities. He was interested in this topic due to his passion for educating all students.

All the volunteer participants were eager to share information about their experiences and expressed interest in the research topic. Their backgrounds had similarities and differences but each person discussed concerns about students with disabilities. Only one participant had administrative experience (Dean and Vice President) and one had a degree in higher education administration. There was only one faculty member who disclosed having a family member with a disability. Two individuals had degrees in education with teaching experience prior to their careers in higher education. All participants were teaching faculty and one was also an academic advisor. Among the participants only one had completed coursework in their postsecondary education program addressing working with students with disabilities. All expressed interest in STEM and assisting students with disabilities. Throughout the interviews it was apparent that the participants wanted to know more about the services offered by the institution and other sources to help them assist students with disabilities. These commonalities among participants informed the themes that emerged from the interviews.

\subsection{Themes}

The following section presents themes that emerged from the data analysis of the five participants' interview transcripts. The five emergent themes included: Challenges, Support, Knowledge of Accommodations and Disabilities, Awareness/Visibility of Disabilities, and Formal versus Informal Accommodations.

\subsubsection{Challenges}

Participants encountered a broad range of challenges or difficulties when working with students with disabilities, ranging from planning and space environment barriers, to optimizing instructional modes and materials despite procedural restrictions. In terms of planning and space environment, most participants discussed that they spent a great deal of time scheduling extra test time and preparing special classrooms for students receiving separate tests or double-time accommodations. Some participants needed the help of other faculty members or teaching assistants (TA's) for proctoring exams for students with disabilities. Large class sizes (upwards of 100 students) led to faculty struggles with accommodating the needs of students with disabilities within limited class time. To optimize instruction for students with a physical disability, the faculty members believed they needed monetary resources to buy instructional materials (e.g., braille textbooks, 3D-print models)to accommodate these students. However, most participants were not aware that it was the student's responsibility to request the required instructional materials from the technology department at the 
institution. For most students with learning disabilities, participants described difficulties in controlling the pace of lectures and providing an adequate lecture (e.g., more verbal cues, preparing class materials in advance, using more graphics and bigger fonts in slides, additional PDF textbooks, recorded lecture notes, and accessible videos). One participant (Karen) shared the pressure she experienced with advance preparation of lecture materials, "the hardest part is I have to do everything in advance." Unlike undergraduate level courses; there were other challenges associated with teaching graduate level courses. For instance, Patricia shared her challenges from teaching a discussion-oriented class, "because it was a graduate course... how do you evaluate a student [with disabilities] in discussion... it was very hard to grade."

In terms of procedural restrictions, one of the biggest challenges was confidentiality. Most participants agreed that it was difficult to identify and help students with learning disabilities due to confidentiality. Unless students disclosed the nature of their disability, faculty members were not informed of the nature of the student's disability beyond the basic accommodations the student received. One of those interviewed (Peter) described the difficulties of collaborating with other faculty members to assist students: "that's the confidentiality factor, helping students from a collaborative standpoint, no, that would be against the law."

The challenges provided a broad spectrum of issues showing the complexity of assisting higher education faculty. Instructors had limited control over what they could adjust in certain cases. Some challenges such as pedagogical methods could be adjusted directly by the instructor as opposed to challenges such as finding funding needed to accommodate students. What the law allows and requires institutions to do helps or limits the assistance a faculty member can provide. Faculty members relied on each other for assistance, and presenting these issues may help to adjust future policy and practice.

\subsubsection{Support}

Support was discussed as it refers to the intellectual mentoring or guidance needed to better assist students with disabilities. All participants found that they received support through various on-campus resources. For some the support was institutionally based, while for others it existed in their departments and from colleagues. Helen explained that, "there are a lot of advising workshops that are run out of university studies and that oversee university advising there. I think that [Institutional Office] for students with disabilities posts things; you know they're always there to answer questions for sure." All participants stated that the institution offered resources that help with testing arrangements for students with disabilities to receive double-time. Additionally, some of the participants received help from their departments to proctor exams. The department culture allowed participants to feel they could call on anyone in the department to help proctor a test (e.g., TA or a fellow colleague).

Participants explained that they themselves offered support to incoming faculty members about ways to serve students with disabilities. Mary, who worked directly with undergraduate students mentioned that there had been some challenges with faculty members who may not understand that accommodations for students with disabilities was mandatory, "so I have to have a very frank conversation with the faculty member saying 'Look, you have to. This is how we do this here, and here's how I can help." Faculty members demonstrated an interest in better serving students with disabilities and found a way to support one another throughout the process.

For some faculty members the best support received was from the students with the disabilities themselves. Faculty members described experiencing this when students are able to take ownership of their learning, they tend to take a "proactive" role in designing accommodations. These accommodations became more challenging to design as the interactive nature of a class increased. Karen explained that in her science class she needed to show a blind student how to build models with electrons and bonds, "so instead of sitting there thinking about 'what are we going to do,' [the student] said 'well in the past I had a felt board,' and so we got that, I think [Institutional Office] got her that, so [the student] has been very proactive in saying 'this is how I can handle this." For the participants, receiving feedback from students who knew their disabilities helped to design effective classroom accommodations.

Although participants described experiencing support from a variety of sources on campus, they all made recommendations that would better prepare them to serve students with disabilities. These recommendations included making the process of notifying faculty about students' disabilities and special accommodations less "mechanical" (Patricia). Faculty were interested in receiving more information than the standard "double-time" accommodations. The participants wanted to learn more information about existing disabilities. Meanwhile, other faculty members believe that as a professor the solution was not a "one-size fits all answer," but explained that "you identify what your individualized instructional needs are or areas for improvement and you act accordingly" (Peter). 
Departmental structures within a college had been beneficial in creating a collaborative environment for faculty members to provide support for each other. All faculty members expressed still requiring more support beyond their department and the institutional office. Overall, participants expressed needing more training on providing accommodations beyond the standard double-time and separate room accommodations. Faculty members stated the importance of having students advocate for their self and the importance of them being a part of the accommodation process. This holistic support approach provided input from multiple parties and lessened the burden on the institution and faculty.

\subsubsection{Knowledge of Accommodations and Disabilities}

Another emerging theme across all interviews was the knowledge of accommodations and disabilities. This theme included sub-themes such as awareness of disabilities and accommodating services, teaching experience and preparation, alternating pedagogical approaches, the process for accommodating students with disabilities, and knowledge of the services provided by the technology and faculty development offices on campus. Each participant alluded to these sub-themes to varying degrees and held similar experiences. For example, all participants stated that they were currently teaching and that as their years of experience increased so had their knowledge of students with disabilities. One of the participants, Karen, stated that over the years, "it may not sound like a big deal but I have a dozen students with learning disabilities." However, experience had mostly been gained on the job, excluding one participant, who had no formal educational opportunities working with students with disabilities. Participants stated that their amount of preparation for working with students with disabilities prior to their current position significantly impacted their knowledge needed to work with these students.

Participants' knowledge of the institutional services provided for students was also evident throughout the interviews. Many identified specific programs or departments (e.g., technology offices, faculty development office) on campus that could assist in accommodating students with disabilities. As Peter suggested, "well, the faculty development institute has a lot of stuff. They also have a special office, which has opportunities to prepare faculty members." All participants, even if they had not attended institutes or professional development, were at least aware of opportunities that existed on campus. One recommendation that emerged relating to opportunities for additional training was described by Mary who stated, "making sure there's enough resources at the institutional disabilities office to support the campus population of students that have disabilities is probably important in my opinion."

All the participants stated in some form that there was a process in place at the institution for working with students with disabilities. The initial step in getting assistance included either self-identification, or a notice from the institutional office. As Karen stated, "the [institutional office] will usually contact me for something that's a little more than just a learning disability to let me know that this is coming." This also showed the awareness that many participants possessed to find out the type of disability a student had if the institution identified them as requiring accommodations. Many believed that this was a more complex case or needed additional accommodations compared to students who approached the faculty member without notice from the institutional office.

Also, all of the participants alluded to changes in pedagogical approaches they had made to support students with disabilities. As Patricia informed the researchers, "at least now I'm trying to move away from this model which is that the faculty is the center and I'm talking most of the time." Beyond changing approaches based on the needs of students, the participants also showed knowledge of pedagogical approaches that could help all students. Helen stated, "I feel strongly that when students are more actively engaged, that most of the learning disabilities will be better accommodated. There are ways to individualize and when students are working in teams, especially if we are attentive to making these teams as diverse as we can, then they can really support one another and utilize different sets of strengths to all learn better." All participants described their knowledge of successful pedagogical practices that could be provided for students with disabilities to fully participate in class.

It was evident from the interviews that preparation and experience played a critical role in informing higher education faculty members about accommodating students with disabilities. All of the participants were aware of the institutional office for disabilities, but regardless of years at the institution were not aware of many details about the office. The participants did not perceive the technology offices and institutional disability office established to assist faculty members in working with students with disabilities as well advertised. They all expressed their desire to seek assistance on how to accommodate students with disabilities but were unsure who to contact and what services were offered. All participants believed the institution could do more to notify them of the resources available.

\subsubsection{Awareness/Visibility of Disabilities}

Throughout the interviews the faculty members focused on the distinction between physical versus non-physical disabilities in relation to awareness and visibility of student's difficulties. An increased focus and description of the difficulties encountered by, accommodations received by, and personal interaction with students with physical disabilities emerged across interviews. This highlighted increased visibility and understanding of the needs of students with physical 
disabilities despite a higher frequency of students with non-physical disabilities. All participants noted, to varying extents, the distinction between students with physical (e.g., sight impairment, hearing impairment, impairment in physical mobility) versus non-physical disabilities (e.g., learning disabilities, ADHD, psychiatric problems). Patricia described the increased visibility and interactions with students with physical disabilities, "the two students that I've had in the whole past six, seven years that have vision problems are upfront and very obvious. I always see them...but some of the other students, they come to my office only one time and it's something that I sign and they leave and they blend in to the rest of the kids. I don't see them."

Across participants, difficulties defining and understanding the types of disabilities experienced by students with non-physical disabilities emerged, whereas clear descriptions of physical disabilities were apparent to all participants. Patricia stated, "I think most of them are disabilities that first of all we don't know the nature." She also described the behavior of some students with non-physical disabilities, "I can see that while I'm talking to them they are not making much eye contact, they are kind of distracted..." Mary stated, "Outside of the hearing impairment student, everything else is ADHD, extra time on tests needed. That's what I've worked with to date." She also referred to students with social disability, noting departmental lack of understanding and awareness, "the other type of disability I have, I have a student, I've had several students in this department with Asperger's. That's a hard one for faculty to understand...but it's pretty apparent with each of the students."

Within this theme, most participants indicated recommendations for increased knowledge of the difficulties faced by students with non-physical disabilities. Karen, in response to the needs of faculty stated, "I knew about the blind student before it happened, I knew about the deaf student... but most of the time like I said I don't really know the students coming so maybe just some more background on what the particular learning disability is about and is there anything else that I should be doing that I just don't know about." Mary expressed the need for greater faculty knowledge of specific disabilities faced by students, "I think being able to understand what disabilities students have and what challenges students are facing would be useful for our faculty."

From these findings it was apparent that faculty members prefer to have the student or the institution notify them about a student with a disability so that they can accommodate them. Confidentiality of releasing this information affected faculty knowing what students had what disabilities unless the student self-disclosed that information to the instructor. Participants were explicit about needing more training on recognizing non-physical disabilities. This was the greatest obstacle faculty members faced when trying to provide the required accommodations for students. The participants in this study made it clear that they could research disabilities and accommodations, but they needed to know what disability the student had.

\subsubsection{Formal versus Informal Accommodations.}

The final theme that emerged throughout the transcripts was the distinction between formal accommodations and informal accommodations. Within this theme participants continually made the distinction between physical disabilities (e.g., hearing impaired, blind, etc.) and learning disabilities (e.g., extra time needed, copy of class notes, Asperger's, etc.). The physical disabilities were ones that they generally knew how to accommodate. If a student were blind they ordered a braille book, but if a student had a learning disability they were less confident about what accommodations needed to be made. Mary discussed the difficulty of dealing with classroom management issues when a student with Asperger's disrupted the class. The participants alluded to an amount of experience and knowledge needed to accommodate learning disabilities, which are not as obvious as physical disabilities. The physical disabilities had a formal (more systematic) accommodation process provided by the institution's disabilities office, whereas accommodations for learning disabilities varied slightly by student and classroom environments. Accommodations for learning disabilities were more informal, and more difficult for faculty to implement.

One way formal accommodations were viewed by the participants were as legal binding accommodations that were required by law, and informal accommodations were viewed as classroom accommodations teachers made without being required. Karen shared this as a problem that she has to address with newer faculty, "when they (students) say that they get these testing combinations, we are legally bound to give them that." Patricia recognized what she is legally required to provide for students with disabilities and what she provides as extra support to better serve the student, "they [students] think that this is their right and we have to do this, but personally when they come to me, I try to put in a little bit extra effort at least in terms of personal communication." Some faculty recognized that the law requires accommodating for students who self-disclose their disability, while some faculty had never been exposed to this process. This could create a problem within the college if a student was not provided the accommodations to which they were legally entitled.

The researchers also found that participants viewed accommodations as systematic support versus informal support, or as adjusting standard modifications that no longer support the dynamic changes within today's classroom. Patricia discussed wanting to use an inverted classroom which requires increased reading and preparation by students before they come to 
class. She expressed difficulty accommodating for this if a student has to receive extra time to prepare for the class, this may slow down the rest of the class or that student may fall behind quickly. Karen discussed the challenge of providing accommodations for a blind student when she used three-dimensional modeling to teach about atomic structure. Karen had to be creative and discuss ideas for accommodations with that student. Karen and the student determined that the student would be able to understand the concept through handling a physical model made by the instructor since the student could not see the computer generated model on the screen. This example provided another emerging issue that educators face regarding how to accommodate these new classroom technologies for students with disabilities.

The participants again reiterated the difficulty with recognizing and accommodating students with non-physical disabilities. Specifically they were unsure of the pedagogical accommodations that needed to be made as opposed to the more formal ones such as double-time. All faculty members interviewed believed that learning disabilities and certain forms of autism were among the most difficult disabilities to recognize and accommodate for. There were some variances among participants in the knowledge of the legal responsibility to make accommodations for students with disabilities. Some were well aware what the law stated while others had never been exposed to this. Lastly, the faculty members all expressed concerns with accommodating new technologies and pedagogical methods. They faced a tension between creating an engaging learning environment and accommodating those newer practices for students with disabilities. Ultimately, all professors described being able to work with the student and the university to accommodate all lessons to some capacity.

\section{Discussion}

Together the accounts of these STEM faculty experiences paint a broader picture regarding the available support needed for delivery of services, issues surrounding students with disabilities at the institution, and the potential unmet needs of some students with disabilities in this college-age population. All study participants had experiences working with and accommodating a range of students (both undergraduate and graduate) with disabilities, though these experiences and training were varied. At this institution faculty members had a number of resources available to serve students with disabilities. All faculty members discussed their legal requirement to accommodate students with disabilities, resulting from Section 504 (1973) and the ADA (1990) which mandates access to higher education, in addition to knowledge of formal procedures to provide services to students with disabilities on the campus. Additionally, a climate of support in the provision of services to students with disabilities emerged through the interviews, at the institutional, departmental, faculty-mentor, and student levels.

Despite participants' awareness of their legal requirements to accommodate students with disabilities and the availability of support at this institution, a number of unmet needs emerged through the faculty members' discussions of their experiences. Throughout this study it was identified that higher education STEM faculty are often unprepared for working with students with disabilities. As Mary stated, "a lot of times faculty go in straight from bachelor's to master's to Ph.D. without any real classroom management experience. So learning how to handle those things [disabilities] just kind of happen as you experience a student with that situation in your classroom." Additionally, participants' difficulties describing non-physical disabilities and limited awareness of the needs of students with non-physical disabilities were apparent. This finding was consistent with the state of the literature reflecting the use of a diversity of unspecified or unclear terms to describe students with disabilities, "in a qualitative review of studies examining students with disabilities in a higher education journal, an emergent theme across studies was 'participant label ambiguities"' (Quick, Lehmann, \& Deniston, 2003, p. 820). Thus, given previous literature and ambiguity of terms, faculty members' difficulty defining and understanding the needs of students with non-physical disabilities was not surprising.

One emergent barrier in faculty members' understanding of the needs of students with disabilities was laws related to confidentiality, preventing faculty from learning the nature of students' disabilities without students' self-disclosure. The unclear nature of non-physical disabilities is potentially problematic given the increased number and diversity of higher education students with disabilities (Henderson, 1999). A larger number of students with learning disabilities are entering higher education, in addition to more disabilities related to a mental illness or emotional disorder compared to hearing or visual impairment (Horn \& Berktold, 1999). Indeed, several faculty members expressed a lack of knowledge regarding the needs of students with non-physical disabilities, including students with emotional, attention deficiencies, and social difficulties.

Faculty members' descriptions of practical and resource challenges to provide services to students with disabilities were indicative of a gap in support. Notable challenges faced by participants included the time required to make room reservations and arrange for proctoring of exams, large class sizes hindering their ability to make structural modification to meet a range of students' learning needs, the need for advanced preparation of materials, and the high monetary cost of some accommodations. Such challenges were perhaps indicative of the need for increased disability support staff, especially given the increasing number of students with diverse needs. 
Finally, some participants' described difficulty in adjusting standard or formal accommodations that no longer support the dynamic changes within today's classroom. Patricia's difficulty in engaging and accommodating students with attention difficulties in the inverted classroom was illustrative of this challenge. The increased changing dynamic of classroom environments within STEM classrooms brings into question the continued appropriateness and adequacy of standard accommodations for non-physical disabilities such as double-time on tests. In particular, challenges seemed to emerge in cases in which the student's disability interferes with their performance in the domain in which they are being evaluated (e.g., class discussion or group presentation assignments for students with social difficulties such as Asperger's), which led to ambiguity in the appropriate accommodations and means to fairly evaluate the student. Future examination of appropriate accommodations in changing classroom dynamics will be necessary within the STEM majors, given the increasing paradigm shift in classrooms (Lage, Platt, \& Treglia, 2000).

\section{Limitations}

This study had several limitations beginning with a number of challenges encountered in the recruitment of participants. The researchers initially sought to exclusively recruit tenure-track STEM professors; however, due to difficulties finding volunteers, inclusion criteria were expanded to include one non-tenure-track STEM instructor. Additionally, one of the STEM professors had experience with students with disabilities, though not at the current institution, possibly leading to unique experiences in comparison to other participants. Another limitation was the varying length of interviews with participants. Each faculty member was interviewed once, potentially limiting the amount of information obtained. Despite such challenges, the faculty members in this study provided a diversity of perspectives of individuals with a range of roles in interacting with students with disabilities.

\section{Implications for Practice and Research}

Important institutional and policy-level implications for the provision of services to students with disabilities in STEM majors were derived from these findings. Limited experiences and minimal training working with students with disabilities experienced by some of the participants denotes the importance of the provision of adequate training in higher education institutions. When higher education institutional leaders assure their faculty members are properly prepared as well as receive quality training and resources to accommodate students of all disabilities, more effective results will occur. This could be done through increased professional development, increased communication from the disabilities office on campus, and instituting pre-service requirements for higher education faculty so that they are better prepared to work with students with disabilities. An emphasis on the provision of education regarding the challenges faced by students with non-physical disabilities and instructional strategies for various forms of learning disabilities may be warranted given participants' difficulty in understanding the needs of such students.

As noted by Lombardi and Murray (2011), given the growing number of students with disabilities entering higher education, greater faculty support in the provision of accommodations may also be warranted. Several participants discussed their difficulties in the practical implications of accommodations due to large class sizes and the planning and resources (e.g., money, space for testing, time for separate testing) required to accommodate students. An institutional level solution may involve greater centralization of the provision of services via institution support offices or the creation of additional disability support staff positions. These positions could be located either at the institutional, college, or departmental level to assist in implementing and planning for accommodations.

At the policy level, changes in the law may be required in the future to accommodate the increasing number and increasing diversity of students with disabilities entering higher education. A particular need for increased specificity in disability-relevant accommodations emerged via the participants' narratives. Given changing instructional practices, with increased emphasis of active student involvement in classrooms and greater use of collaborative projects as means of evaluation in place of traditional exams, the development of new accommodations may be necessary. Many of the traditional accommodations such as extended time on tests and separate testing appear to be less relevant with the use of inverted classroom instructional practices or seminar-based courses in which the means of evaluation do not involve formal test-taking. In particular, accommodations or instructional guidelines for serving students with disabilities impacting their performance in such settings (e.g., ADHD, auditory processing disorder, and Asperger's) are needed. These types of classroom/curricular changes require the involvement and buy-in of aware and educated faculty. Additionally, policy-level adjustment of confidentiality barriers in faculty members understanding the needs and challenges faced by students with disabilities seems warranted. Though such laws are important and were created to protect the rights of students with disabilities, such laws may inadvertently serve to hinder the adequate provision of services to such students and diminish the awareness of the needs of students with non-visible disabilities.

Future research including voices of a larger number and range of STEM faculty members is needed in order to gain a broader perspective of STEM faculty's experiences with students with disabilities. The use of mixed methods designs may be useful in analyzing faculty members' training and preparation to work with students with disabilities and 
perceptions of the greatest needs of students with disabilities, in addition to qualitative descriptions of experiences and challenges experienced by faculty members. Such information, quantifying unmet needs and concerns of faculty members, could add to policy-related decisions within this domain.

Including students with disabilities in future research is also necessary in order to ensure that they have equal voices in the research process. As suggested by Quick et al. (2003), the utilization of participatory action research may be an effective method to obtain information about the day to day reality and unaddressed needs of students with a range of disabilities and include such students in efforts to create and assist in implementation of institutional and policy-level changes. Additional information about students' views on self-advocacy, the relevancy and usefulness of standard accommodations in a variety of classroom settings, and confidentiality issues may be beneficial in making informed policy changes.

\section{References}

Alcorn MacKay, S. (2010). Identifying trends and supports for students with autism spectrum disorder transitioning into postsecondary. Toronto, ON, Canada: Higher Education Quality Council of Ontario. Retrieved from http://www.heqco.ca/SiteCollectionDocuments/ASD.pdf

Americans with Disabilities Act, 42 U.S.C. § 12101 et seq. (1990).

Arscott, W. (2013). Students with learning and developmental disabilities in post-secondary education. Critical Issues in The Future of Learning and Teaching, 8(2), 115-125.

Baker, K. Q., Boland, K., \& Nowik, C. M. (2012). A campus survey of faculty and student perceptions of persons with disabilities. Journal of Postsecondary Education and Disability, 25(4), 309-329.

Chen, X. (2013). STEM Attrition: College Students' Paths Into and Out of STEM Fields(NCES 2014-001). National Center for Education Statistics, Institute of Education Sciences. Washington, DC: U.S. Department of Education.

Dunn, C., Rabren, K. S., Taylor, S. L., \& Dotson, C. K. (2012). Assisting students with high-incidence disabilities to pursue careers in science, technology, engineering, and mathematics. Intervention in School and Clinic, 48(1), 47-54. http://dx.doi.org/10.1177/1053451212443151

Henderson, C. (1999). College freshmen with disabilities: A biennial statistical profile. Washington, DC: American Council on Education, HEATH Resource Center.

Horn, L., \& Berktold, J. (1999). Students with disabilities in postsecondary education: A profile of preparation, participation, and outcomes (NCES 1999-187). Washington, DC: National Center for Education Statistics.

Individuals With Disabilities Education Improvement Act, 20 U.S.C. $§ 1400$ et seq. (2004).

Janosik, S. M. (2005). Anticipating legal issues in higher education. NASPA Journal, 42(4), 401-414.

Kvale, S., \& Brinkmann, S. (2015).Interviews: Learning the craft of qualitative research interviewing.( $3^{\text {rd }}$ ed.). Thousand Oaks, CA: Sage.

Lage, M. J., Platt, G. J., \& Treglia, M. (2000). Inverting the classroom: A gateway to creating an inclusive learning environment. The Journal of Economic Education, 31(1), 30-43. http://dx.doi.org/10.1080/00220480009596759

Larson, P. (2012, July, 18). President Obama announces new plan to create STEM master teaching corps. Retrieved from http://www.whitehouse.gov/blog/2012/07/18/president-obama-announces-new-plan-create-stem-master-teaching-c orps

Lombardi, A. R., \& Murray, C. (2011). Measuring university faculty attitudes toward disability: Willingness to accommodate and adopt universal design principles. Journal of Vocational Rehabilitation, 34, 43-56. DOI: 10.3233/JVR-2010-0533.

Love, T. S. (2013). Addressing safety and liability in STEM education: A review of important legal issues and case law. The Journal of Technology Studies, 39(2), 28-41.

Love, T. S. (2014). Safety and liability in STEM education laboratories: Using case law to inform policy and practice [Electronic supplement]. The Technology and Engineering Teacher, 73(5), 1-13. Retrieved from http://www.iteea.org/mbrsonly/Library/TTT/TTTe/2-14love.pdf

Norman, K., Caseau, D., \& Stefanich, G. (1998). Teaching students with disabilities in inclusive science classrooms: Survey results. Science Education, 82(2), 127-146.

http://dx.doi.org/10.1002/(SICI)1098-237X(199804)82:2<127::AID-SCE1>3.0.CO;2-G 
Ochoa, T. A. (2007). A special case of diversity: Students with disabilities in higher education. In O.G. Brown, K.G. Hinton, \& M. F. Howard-Hamilton (Eds.). Unleashing suppressed voices on college campuses: Diversity issues in higher education (Vol. 19, pp. 193-198). New York, NY: Peter Lang.

Phillips, A., Terras, K., Swinney, L., \& Schneweis, C. (2012). Online disability accommodations: Faculty experience at one public university. Journal of Postsecondary Education and Disability, 25(4), 331-344.

Quick, D., Lehmann, J., \& Deniston, T. (2003). Opening doors for students with disabilities on community college campuses: What have we learned? What do we still need to know? Community College Journal of Research and Practice, 27(9-10), 815-827.

Rossman G. B., \& Rallis, S. F. (2012). Learning in the field: An introduction to qualitative research. ( $3^{\text {rd }}$ ed.). Thousand Oaks, CA: Sage.

Section 504 of the Rehabilitation Act, 29 U.S.C. 791 et seq. (1973).

Seidman, I. (2012). Interviewing as qualitative research: A guide for researchers in education and the social sciences (4th ed.). New York, NY: Teachers College Press.

Shah, N. (2011). More students with disabilities heading to college: Postsecondary options expanding. Education Week, 31(14), 14-15.

Street, C. D., Koff, R., Fields, H., Kuehne, L., Handlin, L., Getty, M., \& Parker, D. R. (2012). Expanding access to STEM for at-risk learners: A new application of universal design for instruction. Journal of Postsecondary Education and Disability, 25(4), 391-408.

Thomas, S. B. (2000). College students and disability law. The Journal of Special Education, 33, 248-257. http://dx.doi.org/10.1177/002246690003300408

U.S. Department of Education, National Center for Educational Statistics. (2012). Students with disabilities at degree-granting postsecondary institutions: First look (NCES 2011-018). Retrieved from http://nces.ed.gov/pubs2011/2011018.pdf

U.S. Department of Education, Office of Special Education Programs, Data Analysis System, (2011).Children with disabilities receiving special education under Part B of the Individual with Disabilities Education Act (OMB \#1820-0043).Retrieved from https://www.ideadata.org/TABLES35TH/B1-1.pdf

U.S. Government Accountability Office. (2009). Higher education and disability: Education needs a coordinated approach to improve its assistance to schools in supporting students (GAO-10-33). Retrieved from http://www.gao.gov/products/GAO-10-33

\section{(cc) $\mathrm{BY}$}

This work is licensed under a Creative Commons Attribution 3.0 License. 